\title{
Подходы к исследованию взаимодействия заинтересованных сторон ${ }^{1}$
}

\author{
Ольга Милёхина ${ }^{\text {I* }}$, Ирина Адова ${ }^{\text {II }}$ \\ ${ }^{\mathrm{I}}$ Новосибирский государственный технический университет, г. Новосибирск, Россия \\ II Новосибирский государственный университет экономики и управления, г. Новосибирск, Россия
}

\author{
Информация о статье \\ Поступила в редакичию: \\ 12.05 .2020 \\ Принята \\ к опубликованию: \\ 09.07.2020 \\ УДК 005 \\ JEL O10, P50, R19
}

\begin{abstract}
Аннотация
Значительный объем научных публикаций при отсутствии единых методологических подходов к исследованию взаимодействия заинтересованных сторон в отечественной экосистеме предопределило актуальность выбранной темы. Проведенный библиографический поиск и контентанализ научных публикаций позволили выделить более 40 наиболее значимых и содержательных монографий и статей, подготовленных отечественными учеными. Дихотомичность взаимодействия заинтересованных сторон трансформирована в четьрехуровневую иерархию, включившую макро-, мезо-, микро- и наноуровни. В статье выполнен обзор подходов и моделей взаимодействия заинтересованных сторон на каждом уровне. Выявлено, что в дополнение $\kappa$ инсайдерам (внутренние) и аутсайдерам (внешние) заинтересованные стороны могут быть как единичными (индивидуальными), так и объединенными общей целью (намерением) в группь. Представлено описание количественных (эмпирические $и$ экономикоматематические) и качественных моделей. В заключение акиентировано внимание на трех апробированных моделях взаимодействия, представленньх в научных публикациях, а именно модели расчета интегрированного показателя общего влияния институичональных единии на деятельность организации; модели интегрированной метрики стратегического прочесса взаимодействия институцииональных единиц для оценки корреляции стратегических иелей и действий институциональных единиц; модели построения и поддержки взаимодействия институциональных единиц на основе создания специализированных семантических порталов на базе технологии открытых связанных данных. Теоретическая и практическая значимость исследования заключается в сформированной авторами системе моделей взаимодействия заинтересованных сторон, которая в совокупности с общепризнанными
\end{abstract}

\section{Keywords:}

holders interaction, systematization and typing models

\footnotetext{
${ }^{1}$ Исследование проведено в рамках Программы стратегического развития НГТУ на период 2017-2021 гг., проект «Формирование механизма взаимодействия заинтересованных сторон в условиях цифровой трансформации бизнес-среды».

* Автор для связи: olga.milekhina@gmail.com
}

DOI: https://dx.doi.org/10.24866/2311-2271/2020-2/60-80 
зарубежными моделями и рекомендаџиями стандартов системы менеджмента качества представляет определенный научный интерес для проведения дальнейших исследований и их имплементации.

\title{
Approaches to the Stakeholders Interaction Investigation
}

Olga Milekhina, Irina Adova

\begin{abstract}
A significant number of scientific publications in the absence of common methodological approaches to investigate the stakeholders interaction in the domestic ecosystem predetermined the relevance of the chosen topic. The bibliographic search and content analysis of the scientific publications allowed identifying more than 40 of the most significant and informative monographs and articles prepared by the Russian scientists. The dichotomous interaction of stakeholders was transformed into a four-level hierarchy that includes macro-, meso-, micro- and nano-levels. The article provides an overview of approaches and models of stakeholders interaction at each level. It was found that in addition to insiders (internal) and outsiders (external), stakeholders could be either single (individual) or united by a common goal (intention) into groups. Quantitative (empirical and economic-mathematical) and qualitative models description was presented. In conclusion, attention was focused on three proven interaction models presented in the scientific publications. Those models are: the models for calculating the integrated indicator of the overall impact of institutional units on the organizations activities; integrated metric models for the strategic process of institutional units interaction to assess the correlation of strategic objectives and institutional units actions; models for building and supporting the institutional units interaction through the creation of specialized semantic portals based on the open linked data technology. The theoretical and practical significance of the study is in the system of stakeholder interaction models proposed by the authors, which together with the generally recognized foreign models and recommendations of the quality management system standards is of certain scientific interest for further research and their implementation.
\end{abstract}

\section{Введение}

Устойчивость функционирования и развития экономики страны требует системного многосубъектного, многомерного и многоаспектного анализа взаимодействия заинтересованных сторон (далее - 3С) макро-, мезо-, микрои наноуровней. При этом его сбалансированность внутри одного уровня может рассматриваться как необходимое условие для организации межуровневого взаимодействия. Методологически важно повысить уровень абстракции и выработать единый подход, позволяющий формировать правила взаимодействия 3 С конкретного уровня иерархии, исходя из требований и ограничений вышестоящего. При этом правила макроуровня, регламентирующие взаимодействия государства, гражданского общества, науки и бизнеса, должны позволить выстроить систему взаимодействия 3С мезоуровня (регионы, отрасли, корпорации). Взаимоотношения между отдельными организациями (3С микроуровня) строятся на основе правил мезоуровня. Взаимодействие ЗС наноуровня (групп людей, решающих задачи для конкретной организации) определяются правилами микроуровня. В нашем понимании подобная конструкция обеспечит системную устойчивость взаимодействия ЗС (рис. 1).

Таким образом, целью настоящего исследования явились сбор, анализ, систематизация и типологизация моделей взаимодействия заинтересованных сторон и выявление моделей, имеющих прикладное значение, когда выводы могут быть использованы в практической деятельности. 


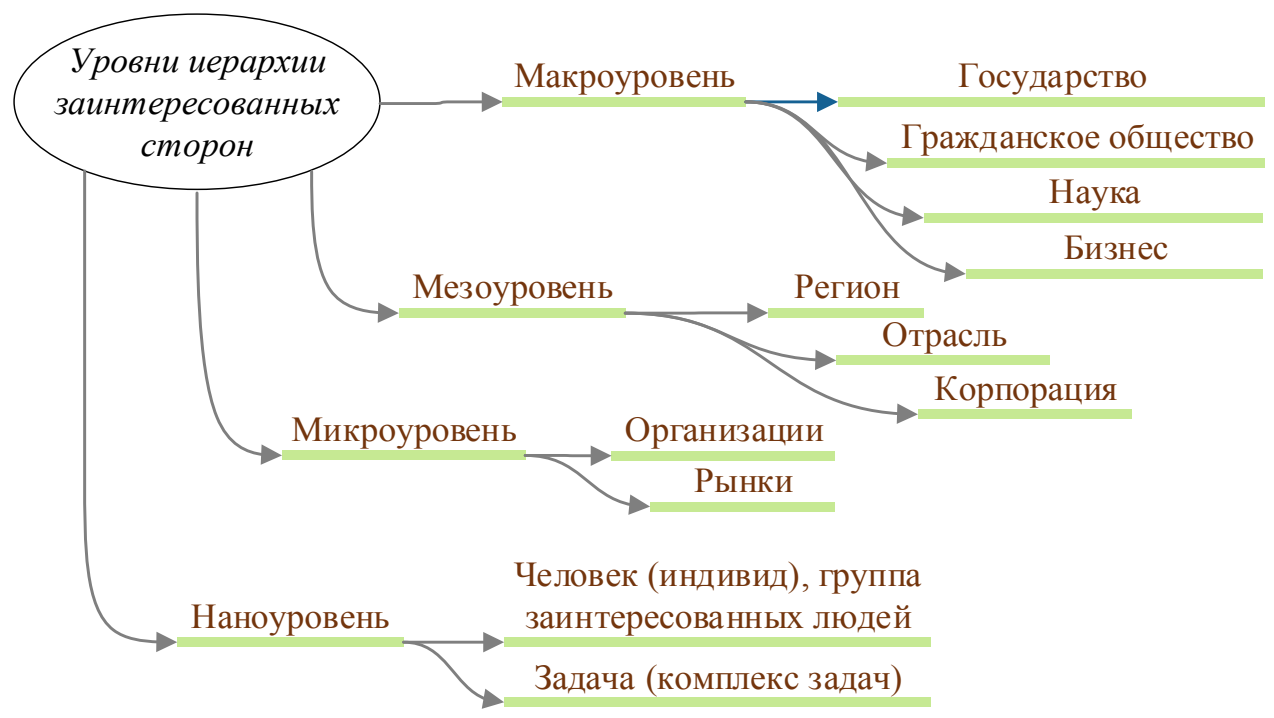

Pис. 1. Уровни иерархии заинтересованных сторон

Источник: составлено авторами

Взаимодействие ЗС вызывает интерес исследователей XX века, и палитра соответствующих моделей, представленных в научных публикациях, экспоненциально растет. По данным научного поискового сервиса Google Scholar первые научные публикации по взаимодействию заинтересованных сторон (англ. stakeholder) к концу 50-х - началу 60-х годов.

Очевидно, что процесс взаимодействия 3С должен обеспечиваться некоей коммуникационной площадкой (до появления компьютеров это могла быть личная встреча, либо письмо на бумажном носителе) и, следовательно, его рассмотрение сквозь призму развития информационнокоммуникационных технологий, позволяет исследования разделить конца прошлого и начала нынешнего века на три этапа:

1) первоначальное накопление знаний на основе автоматизации отдельных задач и функций взаимодействия;

2) дуальное взаимодействие заинтересованных сторон на базе комплексов информационных систем и технологий (информатизация взаимодействия);

3) многомерное взаимодействие систем на основе бесшовных информационных систем и цифровых платформ (цифровизация взаимодействия).

Этап первоначального накопления знаний. В период с 1960 по 1975 гг. обсуждались вопросы, связанные с барьерами и ограничениями взаимодействия людей в основном в области образования и политики. Google Scholar фиксирует 99 публикаций по рассматриваемой тематике за указанный период (рис. 2.)2. Всплеск научной активности 1970 г. можно рассматривать как минимум в трех проекциях: философской, технологической и организационной.

\footnotetext{
2 Здесь и далее графики динамики научных публикаций по теме исследования получены на основе сплошного мониторинга научных публикаций в поисковом сервисе Google Scholar по состоянию на 01 января 2020 года. Поисковый запрос «Модели взаимодействия стейкхолдеров» для русскоязычных публикаций и
} 


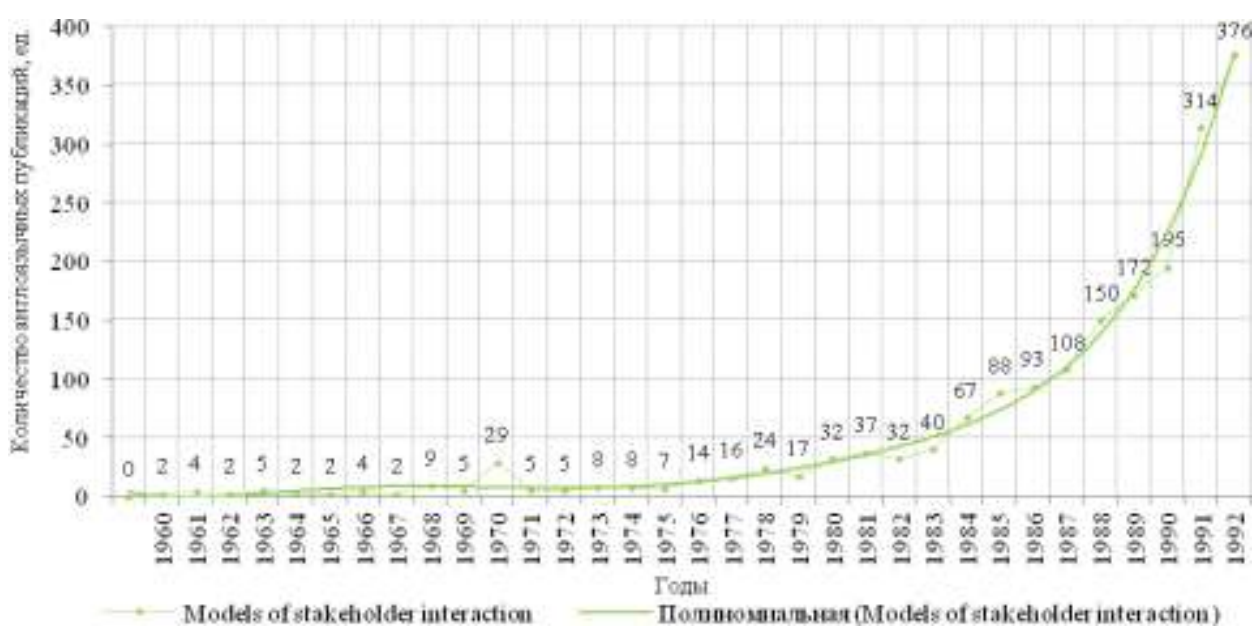

Puc. 2. Динамика научных публикаций по теме исследования за 1960-1992 гг. Источник: составлено авторами по данным сервиса поиска научной литературы Google Scholar

Открытие в 1965 г. закона Мура и проникновение технологических инноваций, связанных с переходом в пятый технологический уклад (1970-2010 гг.), предопределило появление в философской среде термина «информационное общество», предложенного профессором Токийского технологического института Ю. Хаяши ${ }^{3}$. Фиксируя параметры бытия социума, термин удачно воспроизводит специфику глобальных изменений общества, которое становится зависимо от информации [1]. В конце 60-х - начале 70-х годов выходят доклады «Японское информационное общество: темы и подходы [2], «Контуры политики содействия информатизации японского общества» [3], «План информационного общества» [4], в которых информатизация приобретает первостепенное значение, позволяя людям получить надежные источники информации, избавляя их от рутины рабочих процессов через точечную автоматизацию функционала рабочих мест, обеспечивая бесклассовость и бесконфликтность общества и гарантируя высокий уровень потребления [5, 6]. Развитие электроники и микроэлектроники, информационных технологий, программного обеспечения и телекоммуникации позволяет обеспечить значительное повышение скорости обмена данными. Организационные проекции этого периода обусловлены необходимостью более гибкого и адаптивного поведения организаций в условиях повышения турбулентности внешней среды, а также многомерного видения динамики внутренних процессов с целью минимизации возможного ущерба от действий (бездействия) 3С.

Организационный аспект инноваций закрепляет органический подход в практике ведения бизнеса и постулируют необходимость достижения конкретных результатов на основе внутренней мотивации $3 \mathrm{C}[7,8]$.

Структурные сдвиги в экономиках развитых стран [9] и сильнейший мировой экономический кризис 1973-1975 гг., обеспечивший снижение производства в США на $13 \%$, Японии - на 20\%, ФРГ - на 22\%, Великобритании - на $10 \%$, Франции - на $13 \%$, Италии - на 14\%, привели к банкротству предприятий, повышению уровня безработицы и повсеместному падению реальных доходов трудящихся [10], обеспечили импульс к поиску новых возможностей взаимодействия ЗС.

«Models of stakeholder interaction» для англоязычных публикаций с шагом наблюдения один год позволили осуществить параметризацию количества публикаций в каждом году.

3 “Japan's Information Society: Themes and Visions", 1969. 
В основе этапа дуального взаимодействия лежит укрупнение ЗС до уровня взаимодействующих систем, выступающих объектами взаимодействия (например, банков и хозяйствующих субъектов) и усложнение внутренних и внешних связей ЗС в информационную эпоху. Период с 1976 до 1995 гг. характеризуется экспоненциальным ростом количества публикаций с 14 (1976 г.) до 962 (1995 г.). Вопросы укрупнения и усложения взаимодействующих систем рассматриваются с разных позиций - философской (например, [11, 12] и др.), методологической (например, [13] и др.), ситуационной (например, [14] и др.), системной (например, $[15,16,17]$ и др.), технологической (например, [18] и др.). Модели взаимодействия ЗС комплементарны вызовам тех лет: происходят дальнейшие структурные сдвиги в экономиках развитых стран. Они носят системный характер, требуют осмысления и показывают смещение экономического развития в сторону непроизводственных отраслей. Рост информационного сектора экономик развитых стран свидетельствует о переходе от индустриального к постиндустриальному обществу, в котором степень владения информацией порождает текущие и перспективные возможности организаций. Технологические и организационные инновации, отраженные в научных публикациях того периода, предлагают рассматривать взаимодействие ЗС с позиций процессного управления: появляются новые инструменты стратегического управления (например, реинжиниринг бизнес-процессов, [19] и новое видение роли ЗС в условиях роста турбулентности внешней и внутренней среды, экспоненциального увеличения объемов информации, роста доли непрограммируемых решений в процессе управления организациями [20]. Приходит понимание важности управления ценностями конкретных людей, объединенными в группы 3С.

Выступление Г. Ицковица (H. Etzkowitz) на первой международной конференции, посвященной проблемам взаимодействия ЗС (Нидерланды, 1996 г.) положило начало новому этапу - этапу многомерного взаимодействия ЗС. Новая модель, организованная по принципу ДНК и названная «тройной спиралью», объединила три глобальных класса ЗС - университеты, частные предприятия и государство - для создания новых институциональных единиц производства, передачи и применения знаний. При этом, сохраняя предыдущие аспекты рассмотрения, исследования в области технологизации взаимодействия $3 \mathrm{C}$, а также разработки инструментов его реализации (например, $[21,22,23,24,25])$, палитра моделей активно развивается. Количество публикаций за указанный период выросло более чем в 25 раз - с 1290 в 1996 г. до 33100 в 2016, 2017 и 2018 гг. характеризуются некоторым снижением публикационной активности исследователей (рис. 3.).

Таким образом, по данным Google Scholar общее количество англоязычных статей по моделям взаимодействия заинтересованных сторон составляет 382177 единиц. Подобно мировому тренду интерес российских исследователей в обсуждаемой тематике велик: в период 2006-2016 гг. число русскоязычных статей выросло в 27 раз - с 62 до 1674.

2015 г. показал пик прироста научных публикаций, что может являться отражением политических и экономических событий 2014 г.: присоединение Крыма и последовавшие за ним экономические и политические санкции и контрсанкции, девальвация рубля и падение цен на нефть. «Идеальный шторм», который накрыл Россию в 2015 г., заставил активнее искать новых стратегических партнеров на всех уровнях, а также новые способы взаимодействия с ними. В качестве примера макроуровня показателен разворот России на Восток, где отсутствовали санкции, взаимные обвинения и угрозы, были открыты рынки капитала. Как результат - проекты 2014 г. - договоры о поставке газа в Китай и экспорте нефти в Индию. Помимо этого, на ситуацию в значительной мере повлияла распространяющаяся уберизация в глобально изменившая модель ведения бизнеса. Платформенность обеспечила единый формат эффективного исполнения полного цикла отдельных бизнес-функций. 

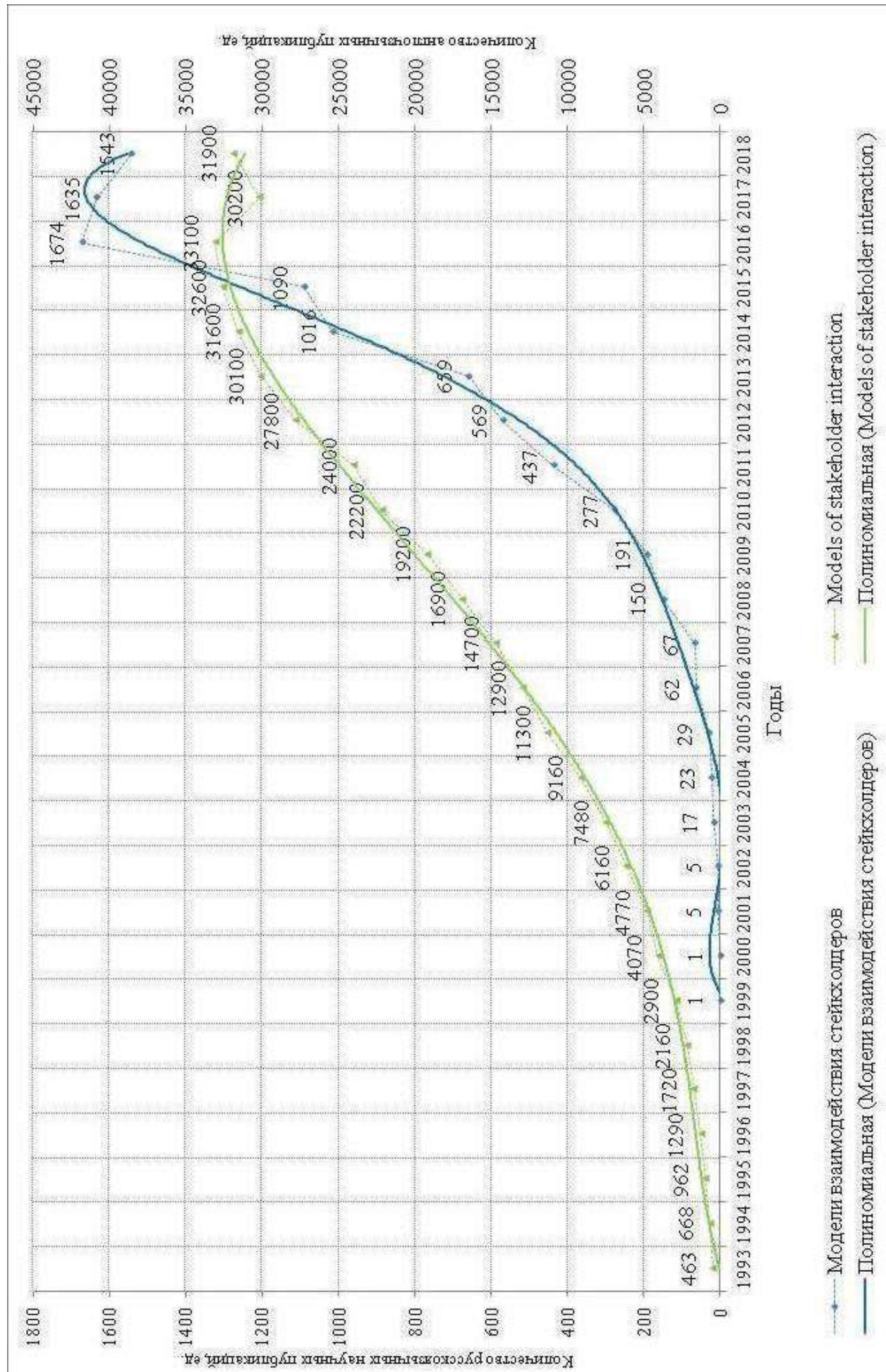

Puc. 3. Динамика научных публикаций по теме исследования за период 1999-2018 гг. Источник: составлено авторами по данным сервиса поиска научной литературы Google Scholar 
Это позволило в краткосрочном периоде минимизировать издержки и риски ведения бизнеса за счет более эффективного взаимодействия независимых субъектов, а в долгосрочном - понимание неизбежности разрушения вертикально-интегрированных структур привело к систематизации лучших практик и активизации исследований в области взаимодействия заинтересованных сторон. С 2017 г. дни наблюдается снижение количества научных публикаций (1635 в 2017 г., 1543 в 2018 г.), которое может быть объяснено некоторым исчерпанием теоретического аспекта рассмотрения данной темы и недостаточной практической применимостью и, как следствие, малым количеством апробированных моделей. Общее количество публикаций - 9451, что составляет $2,47 \%$ от их общемирового числа, что хорошо согласуется с результатами исследований Института статистических исследований и экономики знаний НИУ ВШЭ [26], которые показали, что доля российских публикаций в мире в области гуманитарных наук составляет 2,8\%.

\section{Обзор подходов и моделей взаимодействия заинтересованных сторон}

В целом существующая модельная палитра, описывающая взаимодействие 3С на всех уровнях (макро-, мезо-, микро- и нано-), представлена как качественными, так и количественными моделями. Так, в модели макроуровня И.И. Рахмеевой [27] в качестве ЗС процесса оценивания принимаемых регуляторных решений в субъектах РФ выделяются следующие категории: федеральные и региональные органы власти, органы местного самоуправления, предпринимательское сообщество субъекта РФ, население субъекта РФ, региональные СМИ, научные и учебные организации. Авторская экспликация управляемых параметров функционирования системы оценивания регуляторных решений включает описание ЗС и их групп (через показатели активности и полноты реализации функциональных ролей ЗС и их групп), предметного поля оценки (частота изменений предметного поля и его широта), организационной структуры (статус результатов оценки и распределение функций между органами власти), а также методики оценки (методическая обеспеченность и дифференциация и этапы оценки). Предполагается, что эта макромодель позволит более четко исполнять существующие регламенты выполнения установленных требований к оценке результатов регулирующих воздействий и окажет позитивное воздействие на повышение активности и исполнительности государственных служащих в субъектах РФ, «...будет способствовать формированию благоприятной регуляторной среды и делового климата территорий».

В качестве элементов моделей макроуровня могут выделяться компоненты модели взаимодействия 3С, например, экономические и социальные в модели В.И. Воропаева и Я.Д. Гельруда [28], отраженные в соответствующих показателях официальной государственной статистики (по данным Росстата):

- доходы населения;

-обеспеченность товарами и услугами потребительского назначения;

-обеспеченность жильем, объектами хозяйственно-бытового назначения и коммунальными услугами;

-занятость населения с учетом создаваемых новых рабочих мест, подготовка кадров; 
- обеспеченность населения объектами образования, культуры, здравоохранения, спорта, транспортного обслуживания;

- социальная безопасность;

-здоровье и продолжительности жизни.

Предполагается, что само взаимодействие 3С осуществляется путем реализации конкретных проектов, обеспечивающих повышение благосостоянии общества в целом на основе экономической и социальной стабильности. Каждый проект предполагает несколько сценариев его реализации и последующий экспертный выбор одного из них на основе вектора приоритетов.

Модель Н.Б. Грошевой [29] рассматривает те же компоненты взаимодействия 3С в четырех проекциях - результативности и эффективности использования ресурсов в прошлых и будущих периодах. Помимо указанных выше показателей в ретроспективе (на основе имеющихся фактических данных) учитываются уровень бедности, уровень образования, валовой региональный продукт, объем инвестиций в инновационные проекты и объем поступлений в бюджет. Оценки будущего состояния развития территории представлены в перспективных показателях, таких как индекс развития человеческого потенциала, экологические перспективы, количество потенциальных инновационных проектов, стоимость природных ресурсов, капитализация региона. Традиционно есть много вопросов к перечню показателей статистической отчетности для Росстата, однако, высокая стандартизация, унификация и типизация показателей отчетных форм делает этот подход универсальным: на мезоуровне можно оценивать взаимодействие в отдельных регионах, отраслях, корпорациях, на микроуровне - отдельных организаций. По сути, названные модели отражают результаты деятельности субъектов, но не их взаимодействие.

В модели А.В. Мазуренко [30] взаимодействие 3С рассматривается более широко. Помимо результирующих экономических показателей оценивается процесс коммуникации ЗС. Для этого автором введены следующие группы показателей:

- метрики восприятия территории заинтересованными сторонами, такие, как уровень качества жизни, индекс «гордости за место проживания», удовлетворенности инвесторов и бизнеса, афилированного с рассматриваемой территорией;

- метрики поведения резидентов (местного населения) и нерезидентов (гостей и мигрантов) территории;

- рыночные метрики, позволяющие оценить уровень вовлеченности бизнеса в реализацию городских программ и проектов, соотношение смертность/рождаемость, доля инвестиций местного бизнеса в консолидированном инвестиционном портфеле, оценки места территории в различных рэнкингах.

Модели мезоуровня относительно полно описывают правила взаимодействия ЗС в области медицины и образования. В текущий момент обе отрасли переживают глобальное реформирование, которое должно обеспечить клиент-ориентированную работу, что в перспективе позволит «...стать нужными тому сообществу (community), в котором они локализованы» [31]. Это обязывает оптимизировать работу с ЗС отрасли и, в том числе, на основе формирования новых регламентов деятельности. 
Модельный инструментарий может быть проиллюстрирован следующими примерами:

1) модель взаимодействия вуза с группами внешних 3С, представленная в двух вариантах: а) модель успешности реализации стратегий вуза на основе применения теории нечетких множеств [32, 33]; б) модель расчета интегральной оценки конкурентоспособности вуза на основе частных оценок групп 3С с учетом веса каждой из них на базе использования модифицированной методики SWOT-анализа [34];

2) модели прогнозирования состояний внешней среды образовательной организации (STEEP-анализ) [35] и стратегирования инновационной деятельности вуза на базе опроса 3С с применением модифицированной системы сбалансированных показателей [36];

3) модифицированная модель VRIO Дж. Барни [20, 37, 38, 39, 40] для оценки ресурсов и способности взаимодействия ЗС по четырем параметрам (ценность, редкость, невоспроизводимость и организованность);

4) в работе М.В. Востропятовой [41] описываются игровые модели, например, модель на основе равновесия Нэша для определения равновесных комбинаций стратегий, анализа их социально-экономической эффективности. Получение содержательных рекомендаций по формированию необходимой институциональной инфраструктуры отрасли здравоохранения на основе ожиданий ЗС представлено в игровой модели В.Н. Панурина и И.С. Хана [42].

В качестве модели мезоуровня другой предметной области, описывающей взаимодействие $3 \mathrm{C}$, можно рекомендовать модель предпринимательской экосистемы группы исследователей из Екатеринбурга (Е.Л. Андреева, П.Л. Глухих, Ю.Г. Мыслякова [43]. В зависимости от классификации участников предпринимательской экосистемы (по виду продукции/услуги, основанию создания, отраслевой специфике, форме собственности, динамике развития, организации взаимодействия, степени глобальности и охвата), а также тенденций и вызовов внешней среды, авторы рекомендуют применение разных бизнес стратегий: «Чебурашка», «Клонирование», «Хитрый лис», «Охота на слона». По мнению исследователей, взаимодействие ЗС на основе участия в предпринимательских экосистемах позволит нивелировать угрозы внешней среды и повысить эффективность реализации возможностей глобальных вызовов.

Отдельно выделим комплекс моделей взаимодействия 3С госкорпорации «Росатом», опирающиеся на зарубежные модели и стандарт взаимодействия АA1000 SES-2015 [44]. Результаты опроса отражены в виде карты взаимодействия 3С госкорпорации в рамках подготовки ежегодного отчета о результатах деятельности [45]. В карте параметрически оценивается влияние деятельности Корпорации на внешние 3С и влияние внешних ЗС на Корпорацию. Далее осуществляется принятие решений в четырех проекциях: игнорирование взаимодействия с 3С (одностороннее принятие решений Корпорацией), реагирование (вынужденное взаимодействие в формате ответов на запросы внешних 3С), предупреждение (прогнозирование и предугадывание потребностей 3С) и взаимодействие (между ЗС налаживается постоянное взаимодействие на основе открытости и взаимоуважения).

Однако большая часть спектра формализованных и неформализованных моделей взаимодействия с ЗС ориентирована на микроуровнь. Качест- 
венные модели описывают взаимодействие с точки зрения обоснования признаков классификации ЗС (по уровню власти и заинтересованности в результатах взаимодействия) [46]. Преследуя различные цели исследования, авторы неформализованных моделей формируют:

- соответствующие правила взаимодействия для каждого кластера на основе оценки влияния в зависимости от уровня положительной или отрицательной поддержки ЗС и силы воздействия на проект в модели С.Д. Фурта и Т.Б. Соломатиной $[47,48]$, правил и требований системы корпоративного контроля над результатами внешнего и внутреннего взаимодействия ЗС с целью регулирования неизбежного конфликта их интересов [49];

- разнообразные двумерные матрицы рассматриваемых аспектов взаимодействия, например, на основе сопоставления бенефитов и ожиданий ЗС в ходе реализации программ по взаимодействию в модели А.Ю. Яковлевой и О.А. Писаренко [50], классов 3С и соответствующих стандартов их взаимодействия согласно требованиям международных, межгосударственных и национальных стандартов в модели Ю.В. Долинской [51] и др.;

- структурно-логические и целевые модели для конкретных форм взаимодействия с конкретными ЗС. Разнообразные структурно-логические модели ориентированы, в первую очередь, на выстраивание логики рассматриваемых процессов взаимодействия ЗС, оценку наличия соответствующих обеспечивающих подсистем и конкретных ответственных за результат. Так, например, В.В. Ильюк [52], работая в разных аналитических проекциях, описывает процесс идентификации 3С, моделирует результат взаимодействия ЗС под влиянием стимулов (на основе существенности конкретного стимула, его полно и способности ЗС на адекватную реакцию), алгоритмизирует процесс работы с 3С в наукоемких проектах. На основе модификации моделей Р. Митчелла и Г. Саваж исследовательская группа пермяков (В.В.Грабарь и М.М. Салмаков) структурировала и детализировала процесс взаимодействия на основе довольно удачной классификации основных ЗС проекта и их интересов [53]. В результате формируется целевая модель взаимодействия ЗС в проекциях «взаимодействие / угроза» с локализацией квадрантов «вовлечение - взаимодействие - защита - наблюдение». По мнению авторов модели, наглядное представление всех ЗС позволит выстраивать их мотивационные профили, более гибко предлагать стратегии взаимодействия в целях повышения результативности проектов и вплотную подойти к управлению процессом в контуре с обратными связями. Источником информации для них обычно выступают результаты социологических опросов. Отдельные исследователи пытаются формализовать качественные оценки, полученные в ходе опросов респондентов, и найти способы инструментальной поддержки сбора релевантной информации. Например, группа дальневосточных исследователей (Е.Н. Лихошест, К.С. Солодухин, А.Я. Чен) пытается оценить удовлетворенность ресурсным обменом ЗС через нахождение соответствующей лингвистической переменной (от «полностью неудовлетворен» до «полностью удовлетворен») [54].

В работе А.Г. Поляковой [55] представлен алгоритм взаимодействия с 3С в рамках повышения квалификации и переподготовки специалистов промышленных организаций на основе модели дуального образования. Как 
предполагает автор, внедрение представленного подхода позволит получить выгоды на основе получения разнообразных синергетических эффектов промышленными организациями-работодателями, молодыми специалистам и их семьям, муниципальными образованиям и регионами России.

Д.В. Краснов [56] систематизирует формы и механизмы взаимодействия с ЗС на основе информационного следа (публичной отчетности российских компаний) и концентрирует внимание на выгодах применения современных интернет-технологий и специализированных интернет-порталов, в частности.

Количественные модели микроуровня условно можно разделить на теоретические и апробированные модели. Первые оперируют следующим инструментарием:

1) разнообразными матрицами-дериватами подхода ГК «Росатом»- лояльности 3С (взаимодействие измеряется через отношения «неприязньдоверие») [57], заинтересованности в результатах взаимодействия [58] и др.;

2) сетевыми моделями, отражающими последовательность выбора стратегии взаимодействия [59, 60];

3) балансовой моделью ресурсных отношений 3С с тремя типами обмена - ассиметричного в пользу целевого элемента, эквивалентным и ассиметричным в ущерб целевому элементу (при этом ресурсами считается все, что имеет какую-либо ценность) [61];

4) расчетом разнообразных метрик (например, восприятия, поведенческих, рыночных и экономических) [62];

5) моделями формирования ценности взаимодействия ЗС в проекциях категорий потребностей, внешних условий взаимодействий ЗС как социально-экономических сред существования, поведения ЗС и форм интереса. Так, в модели Е.3. Зиндера [63] методологически корректно реализован принцип декомпозиции потребностей всех категорий 3С с правилами измерения ценностей конкретного уровня и, что не менее важно, - сформированы правила сравнения разных метрик, которые могут быть обладать и качественным, и количественным (натуральными показателями и композитными индексами) шкалированием. Заметим, что помимо данной модели, принцип декомпозиции потребностей реализован только в модели взаимодействия ЗС В.В. Грабаря и М.М. Салмакова [53]. Несомненно, более тонкое рассмотрение категорий стейкхолдеров усложняет модели, однако, делает их более интересными и перспективными для дальнейшего теоретического развития и практического применения.

На текущий момент апробированных моделей взаимодействия $3 \mathrm{C}$, представленных в научных публикациях, не очень много. Авторы пытаются показать читателю возможности применения отдельных математических моделей на примерах решения конкретных управленческих задач. При этом их классы разнообразны: от задач конкретного участника взаимоотношений (например, для заказчика, инвестора, поставщика) до задач фискальных и регулирующих органов (например, разнообразных платежей юридических и физических лиц в модели максимизации налоговых сборов) [64, 65].

Исходя из нашего опыта реализации долгосрочных проектов на крупных промышленных предприятиях, практический интерес могут представлять следующие модели: 
1) модель расчета интегрированного показателя общего влияния ЗС на деятельность организации;

2) модель построения и поддержки взаимодействия ЗС и их групп на основе создания специализированных семантических порталов;

3) модель интегрированной метрики стратегического процесса взаимодействия 3С.

Первая - модель расчета интегрированного показателя общего влияния 3С на деятельность организации, предложенная Ю.В. Новожиловой [66] позволяет произвести расчет показателей общего влияния результатов взаимодействия 3С, а также соответствующие частные показатели. Модель красива и информативна, однако, расчеты были проведены в одной точке - по результатам годовой отчетности конкретной организации в 2011 г., последующие отчеты (2012-2015 годы) декларировали проведение оценки взаимодействия 3С, при этом соответствующие показатели, либо их графическая интерпретация в материалах публичной годовой отчетности указанного периода оказались нам недоступны.

Вторая - модель группы санкт-петербургских исследователей (М.А. Навроцкий, Н.А. Жукова, Д.И. Муромцев, Н.Г. Мустафин) - основана на идее построения и поддержки взаимодействия ЗС и их групп через специализированные семантические порталы на базе технологии открытых связанных данных [67]. Подобные порталы содержат траектории освоения информации взаимодействующими ЗС. В основу построения индивидуальной траектории взаимодействия с 3С и их групп положена четырехуровневая иерархическая модель, включающая уровни инкапсуляции и композиции контента, уровни порождения и композиции конкретных программ взаимодействия. Моделирование результатов взаимодействия выполнено в терминах теории графов. Исследовательской группой разработано два подобных семантических портала;

Третья - модель интегрированной метрики стратегического процесса взаимодействия ЗС И.Б. Гуркова [68] - включает следующие элементы: целеориентированность, позиционирование 3С, образы действий ЗС, стратегичность действий, уровень выполняемых ЗС действий. Апробация метрики проведена посредством опроса 4402 менеджеров (в том числе 1500 генеральных директоров) компаний всех отраслей и сфер экономики 82 регионов РФ. Модель позволяет оценить корреляцию стратегических целей и действий 3 С.

\section{Выводы и перспективы исследования}

Сплошной мониторинг научных публикаций в поисковом сервисе Google Scholar позволил собрать и проанализировать информацию по моделям взаимодействия ЗС. Не претендуя на исчерпывающую полноту описания полученного спектра моделей, их систематизация и типологизация в рамках проведенного исследования позволили выделить четыре признака (по уровню исследования, по группам, по степени формализации и по степени апробации) моделей взаимодействия 3С (рис. 4), относительно которых можно говорить о разрывах в исследованиях и перспективных точках роста, а также и принять решение о векторе наших дальнейших работ. 


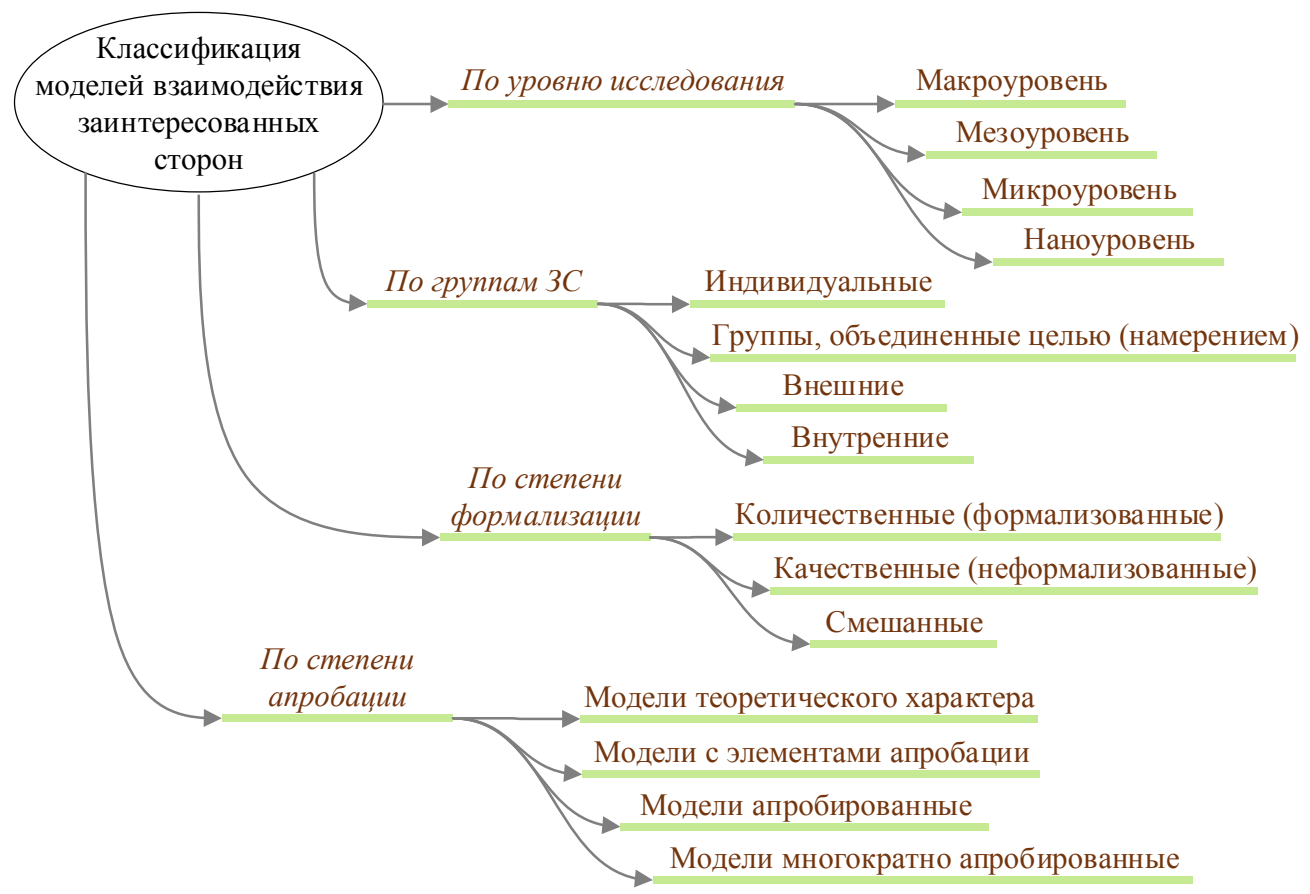

Рuc. 4. Результирующая классификация моделей взаимодействия 3С Источник: составлено авторами

C точки зрения практики (в нашем понимании это принципиальная составляющая рассматриваемой темы) довольно много предстоит поработать с модификацией моделей, а именно:

1) с позиций системной логистики исходных данных (цифровизация экономики будет оказывать помощь в этом вопросе);

2) в части более корректного измерения показателей взаимодействия 3С и групп 3С, а также ухода от лингвистических переменных типа «неприязнь-доверие», абсолютно субъективных и характеризующих респондента в конкретный момент времени, в данном психологическим состоянии и информационной ситуации;

3) в части более тонкой типологизации 3С и групп ЗС с учетом их иерархии в организационной структуре для внутренних ЗС и групп 3С, а также степени влияния на эффективность и результативность рассматриваемой системы (территория, корпорация, организация, программа, проект и т.п.) для внешних ЗС и групп 3С.

$B$ методологическом плане важно найти новые подходы и выстроить модели, позволяющие:

1) сместить акценты в теоретических моделях с ожиданий ЗС и групп 3С на взаимообмен, двусторонние отношения, предполагающие возможность их взаимодействия в контуре с обратными связями; 
2) учесть характер труда, в ходе которого возникает взаимодействие 3С и групп 3С - интеллектуальные и рутинизированные (ординарные) бизнес-процессы требуют разный уровень обеспеченности ресурсами, в том числе временем на локализацию проблемы и поиск вариантов ее решения, непосредственную работу по реализации сценария достижения целей и получение положительного результата;

3) более предметно рассмотреть характер взаимодействия 3С и групп 3С (очевидно, что они представлены конкретными людьми, или агентами взаимодействия, обладающими уникальными моделями мира, компенентностным, культурным и поведенческим багажом, и, следовательно, модели наноуровня, находящиеся пока на периферии научного мейнстрима, должны получить новый импульс к развитию.

В качестве заключения отметим, что последние сто лет продемонстрировали значительное сокращение жизненного цикла организаций более, чем в четыре раза [69], высокую динамику скорости их изменений и создания добавленной стоимости на основе отношений сотрудничества и коэволюции хозяйствующих субъектов, гибкого удовлетворения ожиданий основных заинтересованных сторон и учета их интересов. Время организации бизнеса по принципу феодального хозяйства прошло, и только взаимодействие и слаженная работа ЗС и их групп сможет в обозримый период может принести успех в контексте устойчивого достижения поставленных целей и запланированных результатов.

\section{Список источников / References}

1. Павлов В.Л. Особенности информационного общества. Философия и социальные науки: Научный журнал, 2010, № 1, сc. 77-83. [Pavlov V.L. Osobennosti informacionnogo obshhestva Filosofija i social'nye nauki: Nauchnyj zhurnal, 2010, № 1, pp. 77-83.]

2. Доклад Агентства экономического планирования «Японское информационное общество: темы и подходы». Токио, 1969 [Japan's Information Society: Themes and Visions. Economic Planning Agency, Tokyo, 1969.]

3. Доклад Совета по структуре промышленности «Контуры политики содействия информатизации японского общества». Токио, 1969 [Policy Outlines for Promoting the Informatisation of Japanese Society. Industrial Structure Council, Tokyo, 1969.]

4. Доклад Института по развитию использования компьютеров «План информационного общества». Токио, 1971 [The Plan for an Information Society. Japan Computer Usage Development Institute, Tokyo, 1971.]

5. Алексеева И.Ю. Возникновения идеологии информационного общества [Alekseeva I.Ju. Vozniknovenija ideologii informacionnogo obshhestva]. Available at: http://emag.iis.ru/arc/infosoc/emag.nsf/BPA/99a40acf200e2915c32568b1002fcb16. (accessed 01.01.20).

6. Рукина Н.А. Информационно-коммуникационные технологии: история вопроса и современные проблемы. Вестник Московского университета, 2013, сер.18, №4, cc. 187-193. [Rukina N.A. Informacionno-kommunikacionnye tehnologii: istorija voprosa i sovremennye problemy. Vestnik Moskovskogo universiteta, 2013, vol.18, №4, pp. 187-193.] 
7. Милёхина О.В., Адова И.Б. Подходы к управлению людьми в организации: генезис в условиях непрерывных изменений. Проблемы современной экономики, 2014, №1 (49), cc. 91-96. [Milekhina O.V., Adova I.B. Podhody k upravleniju ljud'mi v organizacii: genezis v uslovijah nepreryvnyh izmenenij. Problemy sovremennoj jekonomiki, 2014, №1 (49), pp. 91-96.]

8. Милёхина О.В. Пути преодоления qwerty-эффектов в социально-экономических системах микроуровня. Материаль $V$ Международной научно-практической конференции студентов, магистров, аспирантов и преподавателей «Непрерывное профессиональное образование: теория и практика». Новосибирск, САФБД, 2014. С. 54-56. [Milekhina O.V. Puti preodolenija qwerty-jeffektov v social'no-jekonomicheskih sistemah mikrourovnja. Materialy 5th Mezhdunarodnoj nauchno-prakticheskoj konferencii studentov, magistrov, aspirantov i prepodavatelej «Nepreryvnoe professional'noe obrazovanie: teorija i praktika», Novosibirsk. SAFBD, 2014. pp. 54-56.]

9. Чибрик М.И. Графический анализ структурных сдвигов в экономике [Chibrik M.I. Graficheskij analiz strukturnyh sdvigov $v$ jekonomike]. Available at: https://cyberleninka.ru/article/n/graficheskiy-analiz-strukturnyh-sdvigov-vekonomike (accessed 01.01.20).

10. Официальный сайт РИА Новости. История мировых экономических кризисов. Справка [Oficial'nyj sajt RIA Novosti. Istorija mirovyh jekonomicheskih krizisov. Spravka]. Available at: https://ria.ru/20080917/151357556.html (accessed 01.01.20).

11. Henderson H. Philosophical conflict: reexamining the goals of knowledge. Public Administration Review. Available at: https://www.sciencedirect.com/science/article/pii/ 0040162576900317 (accessed 01.01.20).

12. Hirsch P., Friedman R. Collaboration or Paradigm Shift: Economic vs. Behavioral Thinking About Policy? Academy of Management Proceedings. Available at: https://journals.aom.org/doi/abs/10.5465/ambpp.1986.4978491 (accessed 01.01.20).

13. Berg M., Chen K., Zissis G. A value-oriented policy generation methodology for technology assessment. Technological Forecasting and Social Change. Available at: https://www.sciencedirect.com/science/article/pii/0040162576900317Stakeholder theory and a principle of fairness (accessed 01.01.20).

14. Keeley M. A Contingency Framework for Performance Evaluation. Academy of Management Review, 1978, Vol. 3, № 3. Available at: https://journals.aom.org/doi/abs/10.5465/AMR.1978.4305716 (accessed 01.01.20).

15. Sage A.P. Systems engineering: Fundamental limits and future prospects. Available at: https://ieeexplore.ieee.org/abstract/document/1456216 (accessed 01.01.20).

16. Chaffee E.E. Three Models of Strategy. Academy of management review. Available at: https://journals.aom.org/doi/abs/10.5465/amr.1985.4277354 (accessed 01.01.20).

17. Thorelli H.B. Networks: between markets and hierarchies. Strategic management journal. Available at:https://onlinelibrary.wiley.com/doi/abs/10.1002/smj.4250070105 (accessed 01.01.20).

18. Ayers T.D. Stakeholders as partners in evaluation: A stakeholder-collaborative approach. Evaluation and program planning. Available at: https://www.sciencedirect. com/science/article/abs/pii/0149718987900383 (accessed 01.01.20).

19. Hammer M. Reengineering work: don't automate, obliterate. Harvard business review, 1990. Available at: https://www.markd.nl (accessed 01.01.20).

20. Barney J.B. Firm resources and sustained competitive advantage. Journal of management, 1991, vol.17, №1, pp. 99-120. 
21. Phillips R.A. (1997). Stakeholder theory and a principle of fairness. Business Ethics Quarterly. Available at: https://www.cambridge.org/core/journals/business-ethicsquarterly/article/stakeholder-theory-and-a-principle-offairness/9F4FAB9FA13963DE75 40222D 9A29147 (accessed 01.01.20).

22. Lewis L.K., Hamel S.A. Communicating change to nonprofit stakeholders: Models and predictors of implementers' approaches. Management Communication Quarterly Available at: https://journals.sagepub.com/doi/abs/10.1177/089331890 1151001 (accessed 01.01.20).

23. Hare M., Pahl-Wostl C. Stakeholder categorisation in participatory integrated assessment processes. Integrated Assessment. Available at: https://www.tandfonline.com/doi/abs/10.1076/iaij.3.1.50.7408 (accessed 01.01.20).

24. Bucolo S., Matthews J.H. Design led innovation: Exploring the synthesis of needs, technologies and business models. Proceedings of Participatory Interaction Conference, Denmark, Sonderborg, 2011. Available at: https://eprints.qut.edu.au/40355/ (accessed 01.01.20).

25. Scheffran J. Tools for stakeholder assessment and interaction Stakeholder Dialogues in Natural Resources Management Springer. Available at: https://link.springer.com/chapter/10.1007/978-3-540-36917-2_6 (accessed 01.01.20).

26. Власова В.В., Гохберг Л.М., Дьяченко Е.Л. и др. Российская наука в цифрах [Vlasova V.V., Gohberg L.M., D'jachenko E.L. i dr. Rossijskaja nauka v cifrah]. Available at: https://issek.hse.ru/news/214886298.html (accessed 01.01.20).

27. Рахмеева И.И. Управляемые параметры системы оценки регулирующего воздействия региона. Управленещ, 2018, т. 9, №5, сc. 48-57 [Rahmeeva I.I. Upravljaemye parametry sistemy ocenki regulirujushhego vozdejstvija regiona. Upravlenec, 2018, vol. 9, №5, pp. 48-57.]

28. Воропаев В.И., Гельруд Я.Д. Математические модели управления для регулирующих органов. Управление программами и проектами, 2013, №4, сс. 272-283 [Voropaev V.I., Gel'rud Ja.D. Matematicheskie modeli upravlenija dlja regulirujushhih organov. Upravlenie programmami i proektami, 2013, №4, pp. 272-283.]

29. Грошева Н.Б. Определение стейкхолдеров инновационных проектов. Современные технологии. Системный анализ. Моделирование, 2010, №4. сс. 240-244 [Grosheva N.B. Opredelenie stejkholderov innovacionnyh proektov. Sovremennye tehnologii. Sistemnyj analiz. Modelirovanie, 2010, №4. pp.240-244.]

30. Мазуренко А.В. К вопросу о разработке универсальной метрики эффективности брендинга территории. Известия Санкт-Петербургского государственного экономического университета, 2014, №1 (85), сc. 106-110 [Mazurenko A.V. $\mathrm{K}$ voprosu o razrabotke universal'noj metriki jeffektivnosti brendinga territorii. Izvestija Sankt-Peterburgskogo gosudarstvennogo jekonomicheskogo universiteta, 2014, №1 (85), pp. 106-110.]

31. Видревич М.Б., Пахальчак Г.Ю. Зачем России европейский опыт встраивания университетов в социум. Управленец, 2018, Т. 9, №2, сс. 26-30 [Vidrevich M.В., Pahal'chak G.Ju. Zachem Rossii evropejskij opyt vstraivanija universitetov v socium. Upravlenec, 2018, vol. 9, №2, pp. 26-30.]

32. Солодухин К.С., Плешкова Т.Ю. Стратегии взаимодействия организации на основе использования ключевых компетенций // Научно-технические ведомости СПбГПУ. Экономические науки, 2008, №1, cc. 223-230 [Soloduhin K.S., Pleshkova $\mathrm{T.Ju}$. Strategii vzaimodejstvija organizacii na osnove ispol'zovanija kljuchevyh kompetencij. Nauchno-tehnicheskie vedomosti SPbGPU. Jekonomicheskie nauki, 2008, №1, ss. 223-230.]

33. Плешкова Т.Ю. Управление отношениями с заинтересованными сторонами как фактор формирования инновационного климата вуза. Дисс. канд. экон. наук. 
Владивосток, 2009. 170 c. [Pleshkova T.Ju. Upravlenie otnoshenijami s zainteresovannymi storonami kak faktor formirovanija innovacionnogo klimata vuza. Diss kand jekon nauk. Vladivostok, 2009. 170 p.] Available at: http://economylib.com/upravlenie-otnosheniyami-s-zainteresovannymi-storonami-kak-faktorformirovaniya-innovatsionnogo-klimata-vuza (accessed 30.09.20).

34. Рахманова М.С. Разработка методов инновационного стратегического анализа вуза на основе теории заинтересованных сторон. Дисс. канд. экон. наук. Владивосток, 2009. 219 c. [Rahmanova M.S. Razrabotka metodov innovacionnogo strategicheskogo analiza vuza na osnove teorii zainteresovannyh storon. Diss. kand. jekon. nauk. 2009. 219 p.] Available at: https://www.dissercat.com/content/razrabotka-metodov-innovatsionnogostrategiches kogo-analiza-vuza-na-osnove-teorii-zaintereso (accessed 30.09.20).

35. Солодухин К.С., Рахманова М.С. Инновационный стратегический анализ вуза на основе заинтересованных сторон. Владивосток, Изд-во ВГУЭС, 2010. 151 c. [Soloduhin K.S., Rahmanova M.S. Innovacionnyj strategicheskij analiz vuza na osnove zainteresovannyh storon. Vladivostok, Izd-vo VGUJeS, 2010. 151 p.]

36. Дзина Г.А. Методические основы управления инновационной деятельностью вуза с позиций теории заинтересованных сторон. Дисс. канд. экон. наук. Владивосток, 2010. 143 c. [Dzina G.A. Metodicheskie osnovy upravlenija innovacionnoj dejatel'nost'ju vuza s pozicij teorii zainteresovannyh storon. Diss. kand. jekon. nauk. Vladivostok, $2010 . \quad 143$ p.] Available at: https://www.dissercat.com/content/metodicheskie-osnovy-upravleniyainnovatsionnoi-deyatelnostyu-vuza-s-pozitsii-teorii-zainter (accessed 30.09.20).

37. Солодухин К.С. Проблемы применения теории заинтересованных сторон в стратегическом управлении организацией. Проблемы современной экономики, 2007, №4 (54), cc. 152-156. [Soloduhin K.S. Problemy primenenija teorii zainteresovannyh storon v strategicheskom upravlenii organizaciej. Problemy sovremennoj jekonomiki, 2007, №4 (54), pp. 152-156.]

38. Солодухин К.С., Луговой Р.А. Стратегическое партнерство с бизнесом как основа развития вузов в Республике Корея и России. Материаль V международной конференции «Новые тенденщии в развитии международного бизнеса» в двух томах. Сеул. Publishing House of Logos; Publishing House of VGUES, 2007, т. 2, cc. 301 -313 [Solodukhin K.S., Lugovoi R.A. Strategic partnership with business as the basis for the development of universities in the Republic of Korea and Russia. New trends in the development of international business. New tendencies in the development of international business. Proceedings of the 5th International Joint Conference in 2 volumes. Seoul: Publishing House of Logos; Publishing House of VGUES, 2007, vol. 2. pp. $301-313$.

39. Рахманова М.С. Методика оценки кадрового потенциала крупных предприятий. Азимут научных исследования: экономика и управление, 2018, т.7, №1 (22), cc. 219-222. [Rahmanova M.S. Metodika ocenki kadrovogo potenciala krupnyh predprijatij. Azimut nauchnyh issledovanija: jekonomika i upravlenie, 2018, vol.7, № 1 (22), pp. 219-222.]

40. Андрийчук В.Г., Колесниченко Ю.Ю. Оценка эффективности использования ресурсов производственного потенциала на основе метода VRIO-анализа. Экономические проблемы развития территорий Украины, 2016, №11 (186), сс. 19-25. [Andrijchuk V.G., Kolesnichenko Ju.Ju. Ocenka jeffektivnosti ispol'zovanija resursov proizvodstvennogo potenciala na osnove metoda VRIO-analiza. Jekonomicheskie problemy razvitija territorij Ukrainy, 2016, №11 (186), pp. 19-25.]

41. Востропятова М.В. Предоставление услуг в сфере здравоохранения на основе стейкхолдерского подхода. Дисс. канд. экон. наук. Москва, 2014. 171 с. 
[Vostropjatova M.V. Predostavlenie uslug $v$ sfere zdravoohranenija na osnove stejkholderskogo podhoda. Diss. kand. jekon. nauk. Moskva, 2014. 171 s.] Available at: https://www.dissercat.com/content/metodicheskie-osnovy-upravleniyainnovatsionnoi-deyatelnostyu-vuza-s-pozitsii-teorii-zainter (accessed 30.09.20).

42. Панурин В.Н., Хан И.С. Стратегии взаимодействия стейкхолдеров в системе обязательного медицинского страхования: формирование игровой модели // Интернет-журнал «Науковедение», 2017, т. 9, №5. [Panurin V.N., Han I.S. Strategii vzaimodejstvija stejkholderov v sisteme objazatel'nogo medicinskogo strahovanija: formirovanie igrovoj modeli // Internet-zhurnal «Naukovedenie», 2017, vol. 9, №5.] Available at: https://naukovedenie.ru/PDF/18EVN517.pdf (accessed 01.01.20).

43. Андреева Е.Л., Глухих П.Л., Мыслякова Ю.Г. Бизнес-стратегии участия компании в предпринимательских экосистемах. Управленец, 2018, т. 9, №6, сс. 4957. [Andreeva E.L., Gluhih P.L., Mysljakova Ju.G. Biznes-strategii uchastija kompanii v predprinimatel'skih jekosistemah. Upravlenec, 2018, vol. 9, №6, pp. 4957.]

44. AA1000 SES-2015 (Stakeholders Engagement Standard) - Стандарт взаимодействия со стейкхолдерами. [AA1000 SES-2015 (Stakeholders Engagement Standard) - Standart vzaimodejstvija so stejkholderami] Available at: https://docplayer.ru/ 61827660-Standart-vzaimodeystviya-s-zainteresovannymistoronami.html (accessed 01.01.20).

45. Итоги деятельности государственной корпорации по атомной энергии «РОСАТОМ». Годовой отчет за 2015 год. [Itogi dejatel'nosti gosudarstvennoj korporacii po atomnoj jenergii «ROSATOM». Godovoj otchet za 2015 god.] Available at: https://ar2015.rosatom.ru/?/ru/54-stakeholder-engagement (accessed 01.01.20).

46. Думова Л.В., Уманский А.А. Проблема идентификации заинтересованных сторон российскими компаниями в рамках функционирования концепции устойчивого развития (на примере металлургической отрасли). Вестник Сибирского государственного индустриального университета, 2017, №3 (21), сс. 63-69. [Dumova L.V., Umanskij A.A. Problema identifikacii zainteresovannyh storon rossijskimi kompanijami v ramkah funkcionirovanija koncepcii ustojchivogo razvitija (na primere metallurgicheskoj otrasli). Vestnik Sibirskogo gosudarstvennogo industrial'nogo universiteta, 2017, №3 (21), pp. 63-69.]

47. Фурта С.Д., Соломатина Т.Б. Карта заинтересованных сторон - инструмент анализа окружения бизнеса. Инищиативы XXI века, 2010, сc. 22-27. [Furta S.D., Solomatina T.B. Karta zainteresovannyh storon - instrument analiza okruzhenija biznesa. Iniciativy XXI veka, 2010, pp. 22-27.]

48. Фурта С.Д., Соломатина Т.Б. Управление стейкхолдерами проекта: ревизия 5-го издания РМBOK® Guide. Инициативы XXI века, 2013. №4, сc. 15-22. [Furta S.D., Solomatina T.B. Upravlenie stejkholderami proekta: revizija 5-go izdanija PMBOK® Guide. Iniciativy XXI veka, 2013. №4, pp. 15-22.]

49. Никифорова Э.Г. Стратегический контроль с модели управления организацией. Российское предпринимательство, 2013, №16 (238), сc . 4-14. [Nikiforova Je.G. Strategicheskij kontrol' s modeli upravlenija organizaciej. Rossijskoe predprinimatel'stvo, 2013, №16 (238), pp. 4-14.]

50. Яковлева А.Ю., Писаренко О.А. Ожидания стейкхолдеров открытой программы - можно ли ими управлять? Научные исследования и разработки. Российский журнал управления проектами, 2017, №1 (18), сc. 15-24. [Jakovleva A.Ju., Pisarenko O.A. Ozhidanija stejkholderov otkrytoj programmy - mozhno li imi 
upravljat'? Nauchnye issledovanija i razrabotki. Rossijskij zhurnal upravlenija proektami, 2017, №1 (18), pp. 15-24.]

51. Долинская Ю.В. Моделирование системы менеджмента для устойчивого развития организации на основе управления отношениями с заинтересованными сторонами. Бизнес-образование в экономике знаний, 2015, №1 (1), сс. 40-45. [Dolinskaja Ju.V. Modelirovanie sistemy menedzhmenta dlja ustojchivogo razvitija organizacii na osnove upravlenija otnoshenijami s zainteresovannymi storonami. Biznes-obrazovanie v jekonomike znanij, 2015, №1 (1), pp. 40-45.]

52. Ильюк В.В. Методологический подход к управлению стейкхолдерами инновационных проектов. Организатор производства, 2016, №4, сс. 38-55. [Il'juk V.V. Metodologicheskij podhod $\mathrm{k}$ upravleniju stejkholderami innovacionnyh proektov. Organizator proizvodstva, 2016, №4, pp. 38-55.]

53. Грабарь В.В., Салмаков М.М. Анализ заинтересованности сторон проекта: методология, методика, инструменты. ARS ADMINISTRANDI, 2014, №2, сc. 36-44. [Grabar' V.V., Salmakov M.M. Analiz zainteresovannosti storon proekta: metodologija, metodika, instrumenty. ARS ADMINISTRANDI, 2014, №2, pp. 36-44.]

54. Лихошест Е.Н., Солодухин К.С., Чен А.Я. Многопериодная модель выбора стратегий взаимодействия организации с группами заинтересованных сторон в стейкходдерской сети с множественными «Центрами власти». Азимут научных исследований: экономика и управление, 2018, №4 (25), сс. 287-290. [Lihoshest E.N., Soloduhin K.S., Chen A.Ja. Mnogoperiodnaja model' vybora strategij vzaimodejstvija organizacii s gruppami zainteresovannyh storon v stejkhodderskoj seti s mnozhestvennymi «Centrami vlasti». Azimut nauchnyh issledovanij: jekonomika $i$ upravlenie, 2018, №4 (25), pp. 287-290.]

55. Полякова А.Г. Интеграция процессов дуального образования и корпоративной социальной ответственности промышленной компании. Управленещ, 2018, т. 9, №2, cc. 31-40. [Poljakova A.G. Integracija processov dual'nogo obrazovanija i korporativnoj social'noj otvetstvennosti promyshlennoj kompanii. Upravlenec, 2018, vol. 9, №2, pp. 31-40.]

56. Краснов Д.В. Формы и механизмы взаимодействия со стейкхолдерами в процессе подготовки нефинансовой отчетности российскими компаниями. $\mathrm{Becm}$ ник МФЮА, 2016, №4, сc. 92-101. [Krasnov D.V. Formy i mehanizmy vzaimodejstvija so stejkholderami v processe podgotovki nefinansovoj otchetnosti rossijskimi kompanijami. Vestnik MFJA, 2016, №4, pp. 92-101.]

57. Доценко Н.В., Гончар И.А., Скрынник А.И., Жебель Ю.Ю. Инструменты управления заинтересованными сторонами. Радиоэлектронные и компьютерные системы, 2015, №2 (75), сc. 150-154. [Docenko N.V., Gonchar I.A., Skrynnik A.I., Zhebel' Ju.Ju. Instrumenty upravlenija zainteresovannymi storonami. Radiojelektronnye i komp'juternye sistemy, 2015, №2 (75), pp. 150-154.]

58. Гусева Ю.Ю., Канцевич В.М., Чумаченко И.В. Мультистейкхолдерная модель управления качеством образовательного проекта. Вісник Національного технічного університету "ХПI". Серія: Стратегічне управління, управління портфелями, програмами та проектами, 2015, № 2, сc. 8-13. [Guseva Ju.Ju., Kancevich V.M., Chumachenko I.V. Mul'tistejkholdernaja model' upravlenija kachestvom obrazovatel'nogo proekta. Visnik Nacional'nogo tehnichnogo universitetu "HPI". Serija: Strategichne upravlinnja, upravlinnja portfeljami, programami ta proektami, 2015, № 2, pp. 8-13.]

59. Воропаев В.И., Гельруд Я.Д. Математические модели управления для руководителя и команды управления проектом (часть 1). Управление проектами и программами, 2014, №1 (37), сc. 62-71. [Voropaev V.I., Gel'rud Ja.D. Matematicheskie modeli upravlenija dlja rukovoditelja i komandy upravlenija 
proektom (chast' 1). Upravlenie proektami i programmami, 2014, №1 (37), pp. 6271.]

60. Воропаев В.И., Гельруд Я.Д. Математические модели управления для руководителя и команды управления проектом (часть 2). Управление проектами и программами, 2014, №2 (38), сc. 55-63. [Voropaev V.I., Gel'rud Ja.D. Matematicheskie modeli upravlenija dlja rukovoditelja i komandy upravlenija proektom (chast' 2). Upravlenie proektami i programmami, 2014, №2 (38), pp. 5563.]

61. Петров М.А. Теория заинтересованных сторон: пути практического применения. Вестник СПбГУ, 2004, сер.8, вып. 2 (№16), сc. 51-68. [Petrov M.A. Teorija zainteresovannyh storon: puti prakticheskogo primenenija. Vestnik $S P b G U, 2004$, ser.8, vyp. 2 (№16), pp. 51-68.]

62. Мазуренко А. В. Формирование ключевых показателей оченки эффективности брендинга территории. Дисс. канд. экон. наук. СПб, 2014. 164 с. [Mazurenko A. V. Formirovanie kljuchevyh pokazatelej ocenki jeffektivnosti brendinga territorii. Diss. kand. jekon. nauk. SPb, 2014. 164 p.] Available at: http://www.dslib.net/economika-xoziajstva/formirovanie-kljuchevyh-pokazatelejocenki-jeffektivnosti-brendinga-territorii.html (accessed 30.09.20).

63. Зиндер Е.3. Направляемый ценностями инжиниринг предприятий // Бизнесинформатика, 2018, №3 (46), сc. 7-19. [Zinder E.Z. Napravljaemyj cennostjami inzhiniring predprijatij // Biznes-informatika, 2018, №3 (46), pp. 7-19.]

64. Воропаев В.И., Гельруд Я.Д. Математические модели проектного управления для заинтересованных сторон. Управление проектами и программами, 2012. № 4, cc. 258-269. [Voropaev V.I., Gel'rud Ja.D. Matematicheskie modeli proektnogo upravlenija dlja zainteresovannyh storon. Upravlenie proektami $i$ programmami, 2012. №4, pp. 258-269.]

65. Воропаев В.И., Гельруд Я.Д. Математические модели проектного управления для заинтересованных сторон. Материалы ХІІ Всероссийского совещания по проблемам управления ВСПУ-2014. Москва. 2014, сс. 8278-8289. [Voropaev V.I., Gel'rud Ja.D. Matematicheskie modeli proektnogo upravlenija dlja zainteresovannyh storon. Materialy XII Vserossijskogo soveshhanija po problemam upravlenija VSPU-2014. Moskva. 2014, ss. 8278-8289.]

66. Новожилова Ю.В. Информационно-аналитическое обеспечение интегрированной отчетности: оценка влияния стейкхоледров на изменение создаваемой стоимости. Статистика и экономика, 2017, т. 14, №1, cс. 44-50. [Novozhilova Ju.V. Informacionno-analiticheskoe obespechenie integrirovannoj otchetnosti: ocenka vlijanija stejkholedrov na izmenenie sozdavaemoj stoimosti. Statistika $i$ jekonomika, 2017, t. 14, №1, pp. 44-50.]

67. Навроцкий М.А., Жукова Н.А., Муромцев Д.И., Мустафин Н.Г. Методология проектирования, разработки и сопровождения доменных семантических порталов научно-технической информации. Научно-технический вестник информациионных технологий, механики и оптики, 2018, т. 18, №2, сс. 286-298. [Navrockij M.A., Zhukova N.A., Muromcev D.I., Mustafin N.G. Metodologija proektirovanija, razrabotki i soprovozhdenija domennyh semanticheskih portalov nauchno-tehnicheskoj informacii. Nauchno-tehnicheskij vestnik informacionnyh tehnologij, mehaniki i optiki, 2018, vol. 18, №2, pp. 286-298.]

68. Гурков И.Б. Интегрированная метрика стратегического процесса - попытка теоретического синтеза и эмпирической апробации. Российский журнал менеджмента, 2007, т. 5. №2, сс. 3-28. [Gurkov I.B. Integrirovannaja metrika strategicheskogo processa - popytka teoreticheskogo sinteza i jempiricheskoj aprobacii. Rossijskij zhurnal menedzhmenta, 2007, vol. 5. №2, pp. 3-28.] 
69. Мэлоун М., Исмаил С., ван Геест Ю. Взрывной рост: почему экспоненциальные организации в десятки раз продуктивнее вашей (и что с этим делать). Москва, Альпина Паблишер. 2017. 390 с. [Mjeloun M., Ismail S., van Geest Ju. Vzryvnoj rost: pochemu jeksponencial'nye organizacii $v$ desjatki raz produktivnee vashej (i chto s jetim delat'). Moskva, Al'pina Pablisher. 2017. 390 p.]

\section{Сведения об авторах / About authors}

Милёхина Ольга Викторовна, кандидат экономических наук, доцент, заведующий кафедрой экономической информатики, Новосибирский государственный технический университет. 630087 Россия, г. Новосибирск, пр. К.Маркса, 20. ORCID ID: 0000-0002-2962-0946.

E-mail: olga.milekhina@gmail.com

Olga V. Milekhina, Candidate of Economic Sciences, Associate Professor, Head of the Department of Economic Informatics, Novosibirsk State Technical University. 20 K. Marks Ave., Novosibirsk, Russia 630087. ORCID ID: 0000-0002-2962-0946. E-mail: olga.milekhina@gmail.com

Адова Ирина Борисовна, доктор экономических наук, профессор, профессор кафедры менеджмента, Новосибирский государственный технический университет. Профессор кафедры Региональной экономики и управления, Новосибирский государственный университет экономики и управления. 630087 Россия, г. Новосибирск, пр. К.Маркса, 20.

ORCID ID: 0000-0002-3339-9121. E-mail: adova.prof@gmail.com)

Irina B. Adova, Doctor of Economic Sciences, Professor, Professor of the Department of Management, Novosibirsk State Technical University. Professor of the Department of Regional Economics and Management, Novosibirsk State University of Economics and Management. 20 K. Marks Ave., Novosibirsk, Russia 630087. ORCID ID: 0000-0002-3339-9121.E-mail: adova.prof@gmail.com) 